\title{
Hereditary elliptocytic anaemia
}

\author{
R. J. L. DAVIDSON AND W. T. STRAUSS \\ From the Departments of Pathology and Medicine, Queen's College, Dundee
}

SYNOPSIS A sibship with four cases of hereditary elliptocytic anaemia is described. The condition in this family may have arisen as a mutation in the mother of the sibship; affected members were unable to taste phenylthiocarbamide while normal members were tasters.

Experiments with ${ }^{32} \mathrm{P}$-orthophosphate in vitro did not show any evidence of biochemical upset as found in hereditary spherocytosis; thus a combination of congenital spherocytosis and elliptocytosis cannot be supported as the cause of the haemolytic state. Clinical evidence of haemolytic disease was accompanied by a tendency to excessive lysis in vitro.

Infection may play a part in the precipitation of anaemic crises in this as in other hereditary haemolytic anaemias.

Elliptical erythrocytes occur as a well recognized hereditary anomaly in man. The first record of elliptical human red corpuscles is usually credited to Dresbach (1904) but Lambrecht (1938) states that the anomaly was observed in 1860 by Goltz. Its inheritance as a regular autosomal dominant has been confirmed in many studies since its nature was first established as familial by Bishop (1914) and as hereditary by Hunter and Adams (1929). Now it is known that in some families at least the elliptocytic trait shows genetic linkage with the rhesus blood groups (Goodall, Hendry, Lawler, and Stephen, 1953; Marshall, Bird, Bailey, and Beckner, 1954; Morton, 1956; Clarke, Donohoe, Finn, McConnell, Sheppard and Nicol, 1960).

Hereditary elliptocytosis is not usually associated with anaemia. Thus, until 1943, only $12 \%$ of recorded cases showed a significant anaemia of haemolytic type (Penfold and Lipscomb, 1943). This hereditary anomaly has to be differentiated from the elliptocytosis occurring in other types of anaemia, notably pernicious anaemia, hypochromic microcytic anaemia, and the anaemias of myelosclerosis and lymphoid neoplasms.

The purpose of this paper is to report a six-year study of the clinical course and haematological investigations of a sibship of seven, four of whom have elliptocytosis with a significant haemolytic anaemia and splenomegaly. One member required cholecystectomy for pigment stones; another derived benefit from splenectomy.

\section{CLINICAL DETAILS}

The propositus, patient II 3 (Fig. 1), a 49-year-old farmworker was admitted to hospital with a five-day history of upper abdominal pain, nausea, vomiting, and slight jaundice. One similar attack two years previously had resolved with conservative treatment. Examination showed epigastric tenderness, slight enlargement of the liver, a palpable tender spleen, and mild conjunctival icterus. His urine contained a trace of bile and excess urobilinogen. Radiological examination of the chest, barium meal examination, and cholecystography revealed
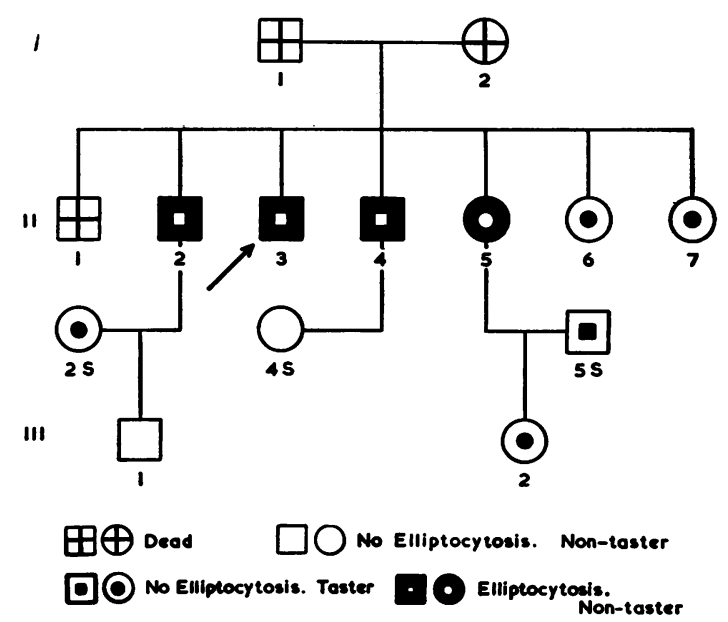

FIG. 1. The pedigree of the affected family. 
TABLE I

HAEMATOLOGICAL FINDINGS IN THE SIBSHIP

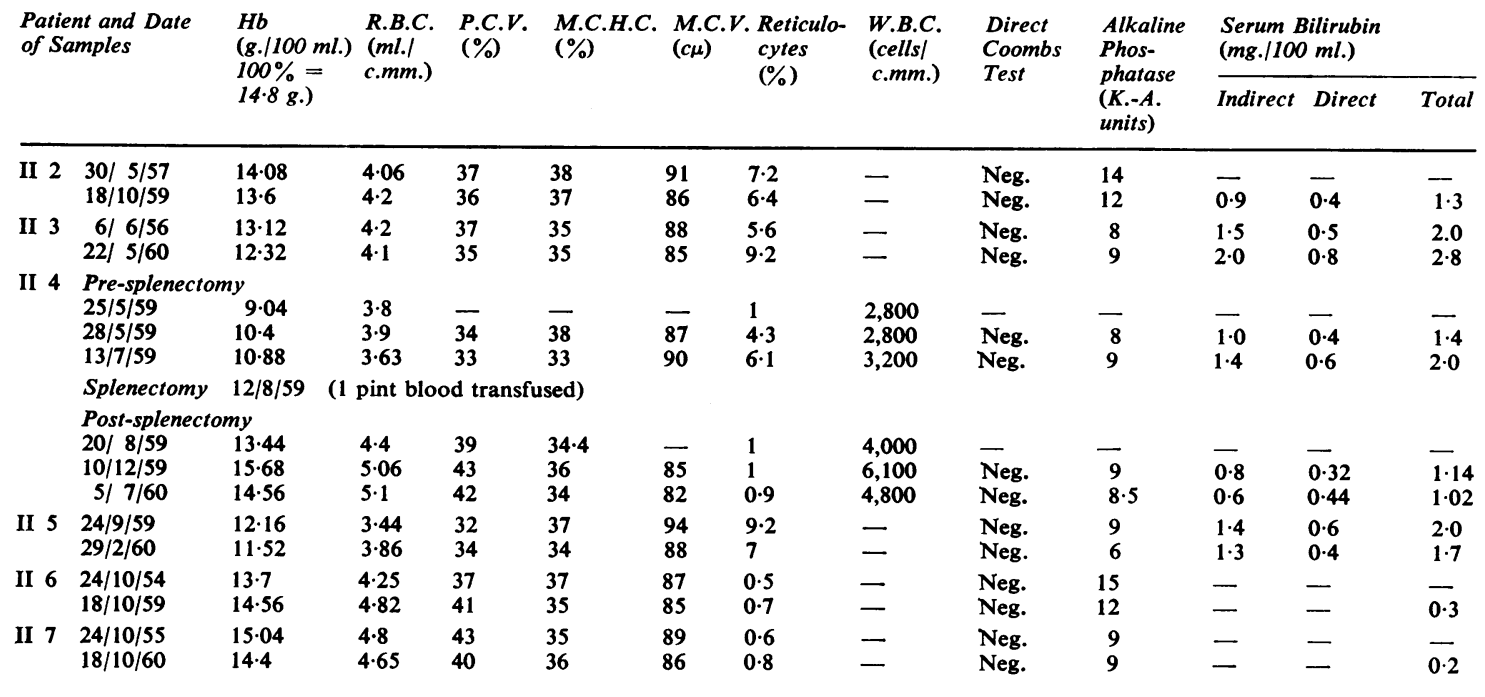

no abnormality. There was a mild normochromic anaemia with $90 \%$ elliptocytes, occasional microelliptocytes and spherocytes, and a reticulocytosis of $7 \%$. Haemolytic elliptocytic anaemia was diagnosed in this patient and his siblings (Tables I to III). Tests of hepatic function showed raised serum bilirubin, thymol turbidity, and cephalin-flocculation values. The patient responded to conservative treatment but on discharge three weeks later the thymol turbidity and cephalin-flocculation levels were still rather high and it was concluded that slight, chronic hepatic damage was present. This was later verified by biopsy. No other sibling has similar hepatic damage.

In January 1957 he suffered a further haemolytic crisis preceded by an attack of bronchitis.

In February 1957 a posterior gastro-jejunostomy was performed for a large posterior duodenal ulcer. At operation it was noted that the gall bladder was normal and contained no calculi, and that the spleen was approximately three times normal size. Liver biopsy showed chronic inflammatory thickening of the capsule, a fibrous scar with round cell infiltration, and a focus of bile-duct hyperplasia. After gastro-jejunostomy his dyspepsia was relieved and he has had no further haemolytic episodes.

PATIENT II 2 This 56-year-old brother had a haemolytic episode at the age of 34 . He was seen by his family doctor who diagnosed 'pernicious anaemia', but he made a spontaneous recovery without specific treatment. Five years later, he had biliary colic for which cholecystectomy was performed at another hospital. The gall bladder contained numerous small pigment stones. He has a compensated haemolytic anaemia (Table I) with slight conjunctival icterus and a palpable spleen.
PATIENT II 4 This 48-year-old brother appears to have the most labile haematological state of the affected members as he has suffered from recurrent nausea, vomiting, weakness, anaemia, and jaundice since childhood.

In May 1959 he was admitted to hospital with pyrexia, epigastric pain, nausea, vomiting, and a cough productive of mucopurulent sputum (Table I). Repeated sputum culture revealed normal flora. Crepitations were heard at the base of the right lung and radiological examination showed slight opacification at the right costophrenic angle. There was no hepatomegaly but the spleen was enlarged and tender. His urine contained no bile, but urobilinogen was detected at a 1:25 dilution by Ehrlich's test. He responded to a course of antibiotics but recurrent crises and anaemia with resultant incapacity for work seemed to warrant splenectomy. After investigation this was performed in August 1959 during a phase of remission (Mr. G. M. Sturrock). At operation the gall bladder appeared normal; in particular it contained no calculi. Liver biopsy revealed no histological abnormality. Marrow biopsy showed a hyperplastic, normoblastic reaction. The normoblasts were round, as were the majority of the polychromatic corpuscles.

The enlarged spleen $(500 \mathrm{~g}$.) was uniformly congested but showed no focal lesion. Imprints from freshly cut surfaces showed only occasional erythrophages. Histological examination confirmed the congestion and showed hyperplasia of the reticuloendothelial cells of the red pulp with diffuse haemosiderosis.

Since discharge in September 1959 the patient has returned to full work. His haematological state has remained stable and satisfactory. Details and comparison of studies performed before and after splenectomy are shown in tables. 
PATIENT II 5 This 47-year-old sister has a life-long history of anaemia, but does not admit to having been jaundiced. At one time she was treated elsewhere with folic acid for a macrocytic anaemia not associated with a histamine-fast achlorhydria. Since coming under observation she has had a fairly well compensated haemolytic state with no crises.

PATIENTS II 6 AND II 7 These sisters of the propositus are symptom-free and have normal blood. They have very kindly acted as normal controls in various investigations.

PATIENT II 1 This brother, who died at the age of 19 from 'spinal trouble', had no history of anaemia or jaundice.

\section{GENETIC STUDIES}

Both parents of the affected sibship are dead (Fig. 1), but it is known that the mother had anaemia, gallstones, and intermittent jaundice.

In order to investigate the possibility of elliptocytosis in collaterals, all living paternal and maternal siblings, i.e., brothers and sisters of $I 1$ and I 2, all their living offspring, and all living offspring of deceased siblings were examined by one of us (R.J.L.D.). Screen tests, made on finger-prick samples, including $\mathrm{Hb}$ estimation (as oxyhaemoglobin in an EEL photoelectric colorimeter), reticulocyte count (Brecher's method), and examination of Leishman-stained films. In preparing the films care was taken to spread them lightly to give a relatively thick smear, as the elliptical shape may be lost by thin, hard spreading. Any member with an abnormal screen test or history of anaemia was more fully investigated, the further investigations including tests of osmotic fragility and autohaemolysis. In all, 27 paternal and 29 maternal relatives were examined. None was shown to have significant anaemia or any familial anomaly of the erythrocytes. As the maternal history is compatible with a haemolytic anaemia and such a condition is present only in her offspring, we think it is likely that this familial elliptocytosis arose as a mutation in the mother of the affected sibship.

A link between the elliptocytosis and the rhesus blood groups was sought, but because of the similarity of the $\mathrm{Rh}$ genotype of the affected and normal members it could not be established. Data on the $\mathrm{ABO}, \mathrm{MN}$, and $\mathrm{P}$ systems were similarly uninformative. On the other hand, a study of their ability to taste phenylthiocarbamide (P.T.C.) showed the four affected members to be non-tasters and the normal members to be tasters. The numbers, however, are so small that linkage could not be established. Among other elliptocytic families, families
3 and 4 of Goodall et al. (1953 and 1954) and family 5 of Lawler and Sandler (1954) have been similarly tested (Lawler, personal communication). The data were such that no conclusions could be reached in families 3 and 4, but there appeared to be independence of tasting and elliptocytosis in family 5 . The findings in this family suggest that future studies of families with hereditary elliptocytosis should include ability to taste phenylthiocarbamide, particularly if there is no evidence of $\mathrm{Rh}$ linkage or if there is a consistently associated haemolytic anaemia.

\section{HAEMATOLOGICAL INVESTIGATIONS}

MORPHOLOGY All members of the sibship have had at least four complete haematological investigations during the period of study, but only the results relevant to the subsequent text are given below.

The affected members all showed a similar red cell morphology with approximately $90 \%$ elliptocytes, occasional microelliptocytes, spherocytes, and cells which tended to crenate even in fresh samples. A variable reticulocytosis was always present. After splenectomy in patient II 4 (Fig. 2) the number of microelliptocytes and spherocytes was significantly increased, as has been noted in several previously reported cases (Dacie, Mollison, Richardson, Selwyn, and Shapiro, 1953; Lipton, 1955; Letman, 1955; Wilson and Long, 1955).

The presence of microelliptocytes and spherocytes in the peripheral blood, the splenomegaly, and the haemolytic anaemia in all the affected members suggested the possible coexistence of congenital spherocytosis and elliptocytosis, and the following investigations were undertaken to see if this combination really existed.

RADIOCHEMICAL INVESTIGATION in vitro The rate of exchange of ${ }^{32} \mathrm{P}$-orthophosphate between plasma and erythrocytes in cases of congenital spherocytosis has been found to be normal (Prankerd, Altman, and Young, 1954, 1955) but it was later found by Tabechian, Altman, and Young (1956) that in the presence of sodium fluoride spherocytes behaved differently from normal red cells. Thus when $\mathrm{NaF}\left(10^{-3} \mathrm{M}\right)$ is added to normal blood there is little or no alteration in the rate of ${ }^{32} \mathrm{P}$-orthophosphate uptake by the erythrocytes, but with congenitally spherocytic cells the exchange process ceases after about one hour and may even be reversed. Two cases of congenital spherocytosis were examined by us and showed the fluoride inhibition but blood from the four siblings with elliptocytosis as well as from their unaffected sisters behaved normally. Patient II 4 gave similar results before and after 


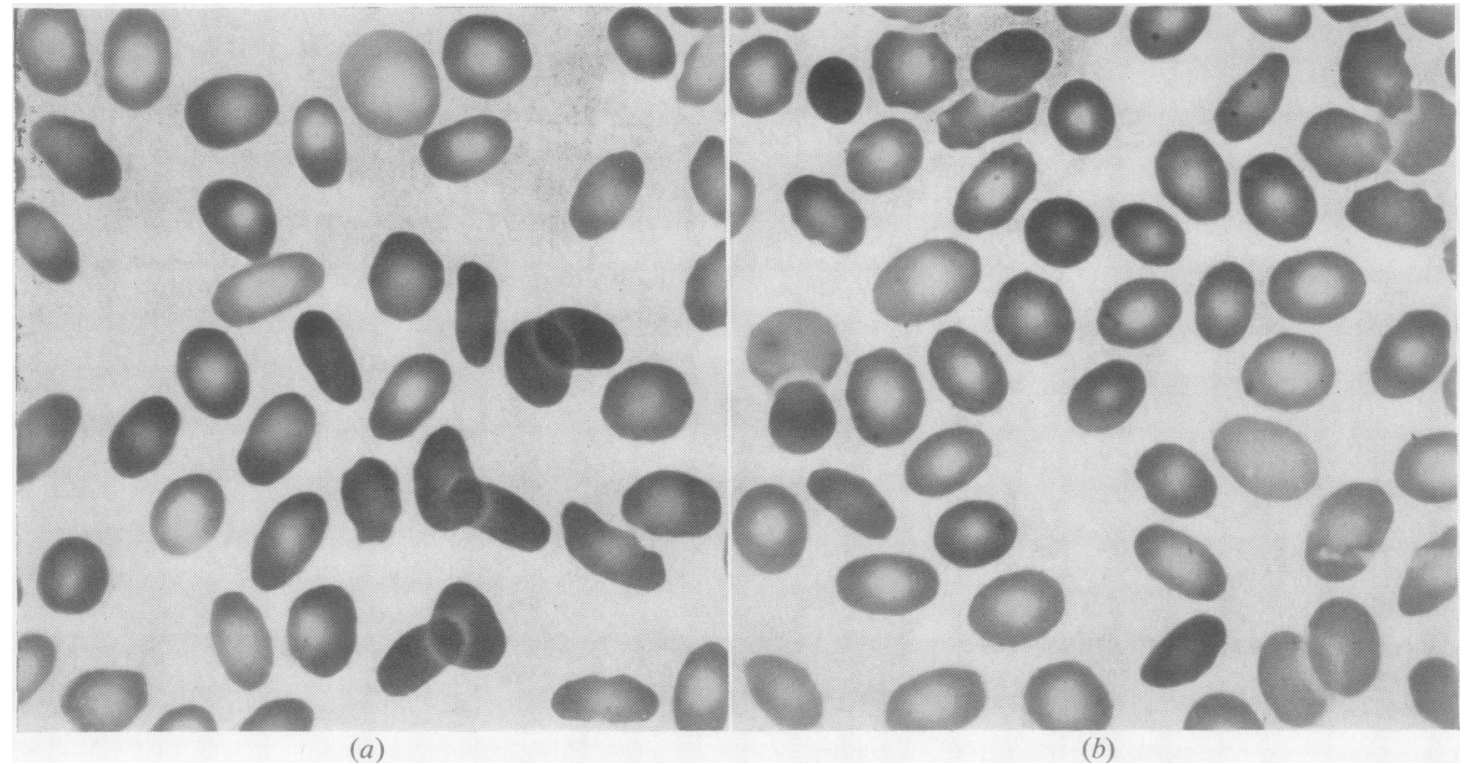

FIG. 2. Blood films (a) before splenectomy and (b) after splenectomy $\times 1,200$.

splenectomy. Thus, from the results of this radiochemical test, we have no reason to believe that either the spherocytosis or the anaemia in our elliptocytic cases was due to a coexistent congenital spherocytic anaemia. Three other cases of familial elliptocytosis with no anaemia and six normal controls likewise showed no inhibition of exchange on addition of NaF. Studies on the 32P-orthophosphate exchange in hereditary elliptocytosis have not been previously reported and details of these findings are to be published elsewhere.

OTHER CHEMICAL INVESTIGATIONS Haemoglobin from the affected siblings showed a normal electrophoretic behaviour and virtually no alkali resistance. Liver function tests (including quantitative estimation of plasma proteins by both precipitation and electrophoresis) were normal except in patient II 3, who showed increased cephalin-flocculation and thymol turbidity levels.

FRAGILITY AND AUTOHAEMOLYSIS TESTS Saline osmotic fragility (fresh and incubated) and autohaemolysis tests were carried out according to Dacie (1960a), except that heparinized blood was used for all tests. The normal values quoted are derived from studies by one of us (R.J.L.D.) on 34 normal men and 30 normal women.

The splenic venous sample from patient II 4 was obtained at the time of operation, after the splenic artery had been ligated. The $\mathrm{Hb}$ level on this sample was $11.5 \mathrm{~g}$. per $100 \mathrm{ml}$; haematocrit $38 \%$. The results of these tests are recorded in Tables $\amalg$ and III. The total bilirubin content of the splenic venous sample was $3.2 \mathrm{mg}$. per $100 \mathrm{ml}$., whereas

TABLE II

OSMOTIC FRAGILITY

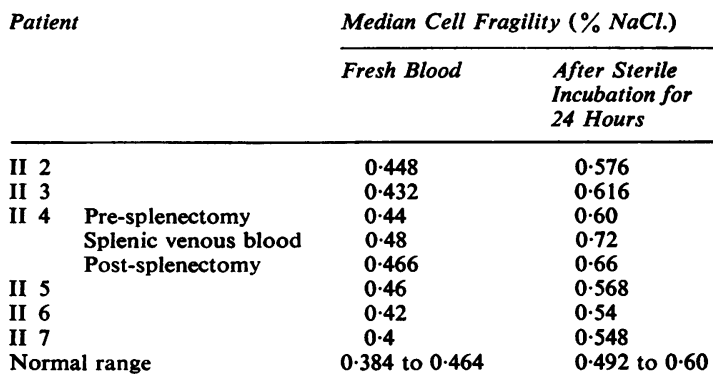

TABLE III

AUTOHAEMOLYSIS

\begin{tabular}{|c|c|c|c|c|c|}
\hline \multirow[t]{3}{*}{ Patient } & & \multicolumn{4}{|c|}{$\%$ Haemolysis } \\
\hline & & \multicolumn{2}{|c|}{24 Hours } & \multicolumn{2}{|c|}{48 Hours } \\
\hline & & $\begin{array}{l}\text { No } \\
\text { Glucose } \\
\text { Added }\end{array}$ & $\begin{array}{l}\text { Glucose } \\
\text { Added }\end{array}$ & $\begin{array}{l}\text { No } \\
\text { Glucose } \\
\text { Added }\end{array}$ & $\begin{array}{l}\text { Glucose } \\
\text { Added }\end{array}$ \\
\hline \multirow{2}{*}{\multicolumn{2}{|c|}{$\begin{array}{ll}\text { II } 2 \\
\text { II } 3\end{array}$}} & $1 \cdot 2$ & 0.3 & $9 \cdot 5$ & $1 \cdot 2$ \\
\hline & & 0.8 & 0.4 & $5 \cdot 0$ & $1 \cdot 3$ \\
\hline \multirow[t]{2}{*}{ II 4} & Pre-splenectomy & 0.6 & $0 \cdot 3$ & 6.0 & $1 \cdot 2$ \\
\hline & Post-splenectomy & $1 \cdot 3$ & $0 \cdot 8$ & $17 \cdot 0$ & $4 \cdot 1$ \\
\hline \multirow{2}{*}{\multicolumn{2}{|c|}{$\begin{array}{ll}\text { II } & 5 \\
\text { II } 6\end{array}$}} & $1 \cdot 0$ & 0.5 & $10 \cdot 0$ & $2 \cdot 3$ \\
\hline & & 0 & 0 & 0.9 & 0.3 \\
\hline \multirow{2}{*}{\multicolumn{2}{|c|}{$\begin{array}{l}\text { II } 7 \\
\text { Normal }\end{array}$}} & 0 & 0 & $1 \cdot 5$ & 0.2 \\
\hline & & $0.0-0.5$ & $0.0-0.3$ & $0 \cdot 5-5 \cdot 0$ & $0 \cdot 1-0.5$ \\
\hline
\end{tabular}


that of a peripheral venous sample was $1 \cdot 1 \mathrm{mg}$. per $100 \mathrm{ml}$.; this marked difference suggests that in this patient the spleen was exerting an excessive haemolytic action on the abnormal erythrocytes.

\section{DISCUSSION}

THE ELLIPTICAL SHAPE In hereditary elliptocytosis the factors determining the unusual shape of the erythrocytes are unknown. As in other such cases, $\mathrm{Hb}$ electrophoresis and alkali denaturation in this family revealed no abnormal haemoglobins. It has been shown, however, by Breuer, De Vries, Peket, and Matoth (1958) that special moving-boundary electrophoretic techniques reveal minor differences between normal adult haemoglobin and haemoglobins from patients with elliptocytosis and other hereditary anaemias; these observers postulate a weakness of the bonds that link the subunits of the haemoglobin molecule and thus the internal structure of these abnormal erythrocytes. The only report of significantly high levels of foetal haemoglobin in adult elliptocytic cases is that of DuclaSoares and Parreira (1958). A structural or enzymic defect of the stroma or cell membrane is a possible but yet unproven explanation of the elliptical shape, and in our cases with haemolytic anaemia at least, such a defect seems probable in view of the abnormal haemolysis in vitro.

OSMOTIC FRAGILITY in vitro The osmotic fragility values of all the affected members in this family were significantly higher than those of the unaffected members and were at or above maximum normal levels. This supports the view that the presence of bizarre-shaped cells, microelliptocytes, and spherocytes is likely to be associated with hyperhaemolysis.

After splenectomy, in patient II 4 there was a significant increase in the osmotic fragility of both fresh and incubated samples, explicable no doubt by the increase of microelliptocytes and spherocytes in the peripheral blood. An increase in fragility in elliptocytosis is generally accepted as occurring after splenectomy, but in only a few cases has a comparison been made with pre-splenectomy values in the same patient, and in these cases the changes varied from a marked increase (Letman, 1955) to no increase at all (Blackburn, Jordan, Lytle, Swan, and Tudhope, 1958). Similarly, in congenital spherocytosis, Young, Izzo, and Platzer (1951) and Dacie (1960b) conclude that there is a further increase in osmotic fragility following splenectomy, particularly as measured on incubated samples.

Study of venous blood from the splenic vein itself has been thus far reported only once in relation to elliptocytosis, no significant differences being noted in the red cell morphology or osmotic fragility range in samples from the splenic vein and artery (Lipton, 1955). In contrast, we found a considerable increase in the osmotic fragility of splenic venous blood in patient II 4 compared with that of peripheral venous samples, and since this could not be explained by any difference in the packed cell volume of the samples it may reflect a splenic action on the cells promoting lysis in a way comparable with that seen in congenital spherocytosis (Emerson, Shen, Ham, Fleming, and Castle, 1956).

AUTOHAEMOLYSIS Reports on autohaemolysis in hereditary elliptocytosis are few and the results inconclusive. In this family the results are similar to those obtained by Dacie (1960c) in his families C, D, and G, namely, that increased levels were found on sterile incubation for both 24 and 48 hours and the addition of glucose greatly reduced the haemolysis but not to normal levels.

After splenectomy our patient II 4 showed a further increase of autohaemolysis. The case D.Hi of family B described by Dacie (1960d) also showed an abnormally high level but had not been studied before splenectomy. The rise in our case and the high level in Dacie's case contrast with the situation in congenital spherocytosis where post-splenectomy autohaemolysis levels tend to be lower than those recorded before splenectomy (Selwyn and Dacie, 1954).

THE HAEMOLYTIC ANAEMIA Most cases of hereditary elliptocytosis have neither clinical nor laboratory evidence of haemolytic anaemia. A minority, however, show various degrees of hyperhaemolysis but the factors determining these grades of severity are only partly understood. The homozygous state, which is so important in the haemoglobinopathies, has only twice been found responsible for severe haemolytic, elliptocytic anaemia (Wyandt, Bancroft, and Winship, 1941; Lipton, 1955).

The presence of spherocytes in the blood of heterozygous subjects with elliptocytic anaemia has led observers in the past to suggest the possibility of a combination of congenital spherocytosis and elliptocytosis as the basis for the anaemia but neither Holst-Larsen (1947) nor subsequent workers have offered any proof of this idea, and certainly the results of our genetic and radiochemical studies are against such a combination. A possible, and, to us, a reasonable explanation of the presence of themicrospherocytes and microelliptocytes is that these small forms are the result of red cell fragmentation (Motulsky, Singer, Crosby, and Smith, 1954).

The rare combination of the elliptocytic trait with 
a haemoglobinopathy is not of any help in the elucidation of the usual type of hereditary elliptocytic anaemia, and, in the known examples of combination with $\mathrm{Hb}$ S (Vandepitte and Louis, 1955) and $\mathrm{Hb} \mathrm{C}$ (Avery, 1956), the abnormal haemoglobin did not appear to potentiate the pathogenicity of the elliptocytosis.

It has been suggested that anaemia may be caused by the combination of the gene(s) for elliptocytosis with another gene which of itself does not cause any detectable change in the blood. Such a possibility was raised by the cases of Mason (1938) and Lendval (1949), where there was a history of an undetermined type of anaemia on the side of the parent not bearing the elliptocytic trait. In sum, there is no convincing proof that the anaemia of hereditary elliptocytosis is due to combination with other genetically determined abnormalities.

INFECTION AND HAEMOLYSIS OR HAEMOPOIETIC DEPRESSION In the congenital haemolytic anaemias it is still uncertain whether the relationship of a casual infection to a clinical exacerbation of the haematological state is an intensification of the haemolysis or a suppression of haemopoiesis, although the observations of Owren (1948), Dameshek and Bloom (1948), and Gasser (1950, 1951) all point to temporary marrow failure as the more important precipitating factor.

All the affected members in our elliptocytic family gave a history of episodes of fever, weakness, and anaemia associated with abdominal pain or respiratory symptoms. Patient II 4 on his first admission to hospital had such an episode with a productive cough but culture of the sputum yielded no pathogenic organisms; the finding of leucopenia in the presence of a mild respiratory infection, anaemia, and a reticulocyte count well below his 'compensated' level certainly suggested that the anaemia was due to a sudden haemopoietic insufficiency. Unfortunately, confirmatory marrow aspiration was not carried out. Campanacci, Torlontano, Tonietti, and Conti (1960) suggested that their two elliptocytic anaemic patients had hypoplastic erythropoiesis, and although no other comparable reports are available, infection seems to have unmasked the presence of previously unsuspected hereditary elliptocytosis by precipitating a severe anaemia in Dacie's (1954) case and that reported by Blackburn et al. (1958).

MEgALOBLASTIC CHANGES The reputedly megaloblastic relapse in Cases II 2 and II 5 were diagnosed elsewhere but not documented precisely enough to be cited as indubitable. We have seen two other cases of elliptocytic anaemia mistakenly diagnosed on the blood film as megaloblastic anaemias. Megaloblastic change is known to occur rarely in cases of congenital spherocytosis and other haemolytic anaemias, particularly in pregnancy, but no adequately proven case has been recorded in a person with hereditary elliptocytosis.

HAEMOLYTIC ROLE OF THE SPLEEN The spleen is usually enlarged and palpable in patients with elliptocytic haemolytic anaemia, but in those patients with merely the trait the spleen is not palpable, and, therefore, probably not enlarged. The haemolytic activity of the spleen has been demonstrated in patient $\amalg \mathbf{4}$ by bilirubin estimation and osmotic fragility tests on splenic venous blood. As in congenital spherocytosis, the cause of the splenic congestion and the mechanisms leading to destruction of the abnormal erythrocytes are largely unexplained. The available evidence suggests, however, that the lytic role of the spleen is secondary to the genetically determined defect of the erythrocytes.

TREATMENT Although the factors responsible for the elliptical shape of the erthrocytes and the pathogenesis of the occasionally associated haemolytic anaemia are far from being adequately understood, there seems little doubt that in the anaemic cases splenectomy alleviates the haemolytic state and improves the physical well-being of the patient. The results of splenectomy are reviewed by Dacie (1960e) and we merely add that in our Case II 4 the operation was of definite benefit.

We thank Professor I. G. W. Hill and Mr. G. M. Sturrock for permission to investigate patients under their care, Professor A. C. Lendrum, Dr. K. G. Lowe, and Dr. Sylvia D. Lawler for reviewing the manuscript, Dr. $\mathbf{H}$. B. Goodall for encouragement and advice, Dr. F. Hutchison for help with the radioactive investigation, and Mr. R. Smith and Mr. J. Corkhill for special technical assistance.

\section{REFERENCES}

Avery, M. E. (1956). Bull. Johns Hopk. Hosp., 98, 184.

Bishop, F. W. (1914). Arch. intern. Med., 14, 388.

Blackburn, E. K., Jordan, A., Lytle, W. J., Swan, H. T., and Tudhope, G. R. (1958). J. clin. Path., 11, 316.

Breuer, M., De Vries, A., Peket, L., and Matoth, Y. (1958). Proc. 6th int. Congr. int. Soc. Hematology, Boston, 1956, p. 749. Grune and Stratton, New York.

Campanacci, L., Torlontano, G., Tonietti, G., and Conti, C. (1960) Minerva. nucleare (Torino), 4, 18.

Clarke, C. A., Donohoe, W. T. A., Finn, R., McConnell, R. B., Sheppard, P. M., and Nicol, D. S. H. (1960). Ann. hum. Genet., 24, 283.

Dacie, J. V. (1954). The Haemolytic Anaemias, Congenital and Acquired. Churchill, London.

(1960a, b, c, d, e). Ibid, 2nd ed. Pt 1. Churchill, London. Mollison, P. L., Richardson, N., Selwyn, J. G., and Shapiro, L. (1953). Quart. J. Med., 22, 79. 
Dameshek, W., and Bloom, M. L. (1948). Blood, 3, 1381.

Dresbach, M. (1904). Science, 19, 469.

Ducla-Soares, A., and Parreira, F. (1958). Sang., 29, 33.

Emerson, C. P. Jr., Shen, S. C., Ham, T. H., Fleming, E. M., and Castle, W. B. (1956). A.M.A. Arch. intern. Med., 97, 1.

Gasser, C. (1950). Sang, 21, 237.

(1951). Die hämolytischen Syndrome im Kindesalter, p. 214. Thieme, Stuttgart.

Goodall, H. B., Hendry, D. W., Lawler, S. D., and Stephen, S. A. (1953). Ann. Eugen. (Lond.), 17, 272.

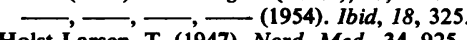

Holst-Larsen, T. (1947). Nord. Med., 34, 925.

Hunter, W. C., and Adams, R. B. (1929). Ann. intern. Med., 2, 1162.

Lambrecht, K. (1938). Ergebn. inn. Med. Kinderheilk., 55, 295.

Lawler, S. D., and Sandler, M. (1954). Ann. Eugen. (Lond.), 18, 328.

Lendval, J. (1949). Lancet, 1, 582.

Letman, H. (1955). Acta med. scand., 151, 41.

Lipton, E. L. (1955). Pediatrics, 15, 67.

Marshall, R. A., Bird, R. M., Bailey, H. K., and Beckner, E. (1954). J. clin. Invest., 33, 790.
Mason, V. R. (1938). In Handbook of Hematology, Vol. 3, ed. H. Downey, p. 2351. Hoeber, New York.

Morton, N. E. (1956). Amer. J. hum. Genet., 8, 80.

Motulsky, A. G., Singer, K., Crosby, W. H., and Smith, V. (1954). Blood, 9, 57.

Owren, P. A. (1948). Ibid, 3, 231.

Penfold, J. B., and Lipscomb, J. M. (1943). Quart. J. Med., n.s. 12, 157.

Prankerd, T. A. J., Altman, K. I., and Young, L. E. (1954). J. clin. Invest., 33, 957.

,$- L$, (1955). Ibid, 34, 1268.

Selwyn, J. G., and Dacie, J. V. (1954). Blood, 9, 414.

Tabechian, H., Altman, K. I., and Young, L. E. (1956). Proc. Soc. exp. Biol. (N.Y.), 92, 712.

Vandepitte, J., and Louis, L. (1955). Rev. Hémat., 10, 19.

Wilson, H. E., and Long, M. J. (1955). A.M.A. Arch. intern. Med., $95,438$.

Wyandt, H., Bancroft, P. M., and Winship, T. O. (1941). Arch. intern. Med., 68, 1043.

Young, L. E., Izzo, M. J., and Platzer, R. F. (1951). Blood, 6, 1073.

\section{Broadsheets prepared by the Association of Clinical Pathologists}

The following broadsheets (new series) are published by the Association of Clinical Pathologists. They may be obtained from Dr. R. B. H. Tierney, Pathological Laboratory, Boutport Street, Barnstaple, N. Devon. The prices include postage, but air mail will be charged extra.

3 The Detection of Barbiturates in Blood, Cerebrospinal Fluid, Urine, and Stomach Contents. 1953. L. C. NICKOLLS. $1 \mathrm{~s}$.

4 The Estimation of Carbon Monoxide in Blood. 1953. D. A. STANLEY. 1s.

5 The Identification of Reducing Substances in Urine by Partition Chromatography on Paper. 1953. G. B. MANNING. $1 \mathrm{~s}$.

6 The Paul-Bunnell Test. 1954. R. H. A. SWAIN. 1s.

7 The Papanicolaou Technique for the Detection of Malignant Cells in Sputum. 1955. F. HAMPSON. 1s.

10 Mycological Techniques: (1) Collection of Specimens. 1956. R. W. RIDDELL. $1 \mathrm{~s}$.

11 Mycological Techniques: (2) Cultural Isolation. 1956. R. W. RIDDELL. 1s.

12 Techniques for Demonstrating L.E. Cells. 1956. J. V. DACIE and L. S. SACKER. Is.

13 The Identification of Serotypes of Escherichia coli Associated with Infantile Gastro-enteritis. 1956. JOAN TAYLOR. 1s.

14 The Determination of Serum Iron and Serum Unsaturated Iron-binding Capacity. 1956. ARTHUR JORDAN. 1s.

16 Preservation of Pathological Museum Specimens. 1957. L. W. PROGER. 1s.

17 Cultural Diagnosis of Whooping-cough. 1957. B. W. LACEY. $1 \mathrm{~s}$.

18 The Rose-Waaler Test. 1957. c. L. GReenbury. $1 \mathrm{~s}$.
19 The Laboratory Diagnosis of Fibrinogen Deficiency. 1958. R. M. HARDISTY. $1 \mathrm{~s}$.

20 Investigation of Porphyrin/Porphyria. 1958. C. RIMINGTON. $1 \mathrm{~s}$.

21 Quantitative Determination of Porphobilinogen and Porphyrins in Urine and Faeces. 1958. C. RIMINGTON. $1 \mathrm{s.}$

22 Investigation of Haemolytic Anaemia. 1959. J. G. SELWYN. 1s.

23 The Dried Disc Technique for Bacterial Sensitivity Tests. 1959. R. W. FAIRBROTHER and J. C. SHERRIS. 1s.

24 Safe Handling of Radioactive Tissues in the Laboratory and Post-mortem Room. 1959. R. c. CURRAN. 1s.

26 The Periodic Acid-Schiff Reaction. 1959. A. G. E. PEARSE 1s.

28 Daily Fatty Acid Excretion. 1960. A. C. FRAZER. 2s.

29 The Preparation of Bone for Diagnostic Histology. 1960. D. H. COLLins. $2 \mathrm{~s}$.

31 Investigation of Haemorrhagic States with Special Reference to Defects of Coagulation of the Blood. 1961. E. K. BLACKBURN. 4s.

32 Detection of Resistance to Streptomycin, P.A.S., and Isoniazid in Tubercle Bacilli. 1961. R. CRUICKSHANK and S. M. STEWART. 2 s.

34 Titration of Antistreptolysin O. 1961. H. GOODER and R. E. O. WILliams. $2 s$.

35 The Estimation of Faecal 'Urobilinogen.' 1961. C. H. GRAY. $2 s$. 